\title{
Tecnologias na Formação de Professores de Matemática: Uma Experiência na Iniciação a Docência
}

\author{
Maria Ivete Basniak ${ }^{1}$ \\ ${ }^{1}$ Universidade Estadual do Paraná - campus de União da Vitória - Paraná (UNESPAR) \\ Praça Coronel Amazonas, s/n - 84600-000 - União da Vitória - PR - Brazil \\ basniak2000@yahoo.com.br
}

\begin{abstract}
This paper discusses the need for teacher's education involving technologies that overcomes the instrumentation in computational artifacts. Assuming as theoretical assumptions works by Bittar (2011), that the teacher needs to integrate the technologies to his pedagogical practice and by Bueno (2013), highlighting his social-historical character, it becomes necessary a training that propitiates discussions and reflections about pedagogical possibilities of the computers use in teaching and learning of mathematics contents. It is reported briefly the work experience in relation to the subproject PIBID: Technologies and Teachers Training for Teaching Mathematics UNESPAR - campus of União da Vitória.
\end{abstract}

Resumo. Discute-se neste trabalho a necessidade da formação de professores envolvendo tecnologias que supere a instrumentação em artefatos computacionais. Assumindo como pressupostos teóricos os trabalhos de Bittar (2011) de que o professor precisa integrar as tecnologias a sua prática pedagógica e de Bueno (2013) com destaque a seu caráter histórico-social, torna-se necessária uma formação que permita discussões e reflexões sobre possibilidades pedagógicas de uso dos computadores no ensino e aprendizagem dos conteúdos de matemática. Relata-se brevemente a experiência de trabalho junto ao subprojeto do PIBID: Tecnologias e Formação de Professores para o Ensino da Matemática da UNESPAR campus de União da Vitória.

\section{Introdução}

Embora tecnologias na educação seja um tema em discussão no Brasil há quase meio século, pois historicamente iniciaram-se na década de 70, com dois importantes eventos na área: o Seminário Intensivo Sobre o Uso de Computadores no Ensino de Física, em São Paulo, na Universidade Federal de São Carlos, ministrado por E. Huggins, e a Primeira Conferência Nacional de Tecnologia em Educação Aplicada ao Ensino Superior (I CONTECE), no Rio de Janeiro, promovida pelo Conselho de Reitores das Universidades Brasileiras, ainda atualmente há muito a se debater sobre o tema.

De acordo com Odorico, et al. (2012) ainda hoje professores que se disponham a utilizar tecnologias digitais durante as aulas enfrentarão inúmeros problemas, entre os quais a falta de preparo para desenvolver um eficiente trabalho pedagógico de forma a promover mudanças positivas no processo de ensino-aprendizagem. 
O presente trabalho discute a necessidade da formação de professores superando a instrumentação em artefatos computacionais e partindo de discussões que permitam reflexões sobre possibilidades pedagógicas de uso dos computadores no ensino e aprendizagem dos conteúdos de matemática.

Assumem-se como pressupostos teóricos os trabalhos de Bittar (2011) em que o professor precisa integrar as tecnologias à sua prática pedagógica, promovendo mudanças reais na metodologia do trabalho do professor e não apenas inseri-las e, de Bueno (2013) em relação à necessidade de uma visão crítica sobre a tecnologia no ambiente escolar, com destaque a seu caráter histórico-social.

Relata-se brevemente a experiência que se teve em relação ao trabalho que se desenvolve junto ao subprojeto do PIBID: Tecnologias e Formação de Professores para o Ensino da Matemática da Universidade Estadual do Paraná (UNESPAR) no campus de União da Vitória, quando se observou resultados mais positivos ao se adotar como uma das formas de trabalho a produção de material através de grupos de estudos utilizando softwares computacionais como recursos para o ensino de conteúdos de matemática.

\section{Referencial Teórico}

Bittar (2011) discute a formação de professores de forma que esses passem a integrar a tecnologia em suas aulas e não apenas inseri-las como um recurso ilustrativo e motivador. A autora apoia suas discussões em conceitos de psicologia de Piaget e "em especial na ideia de esquema definida por Piaget e utilizada e ampliada por Vergnaud (1990), Rabardel (1995) desenvolve a teoria da instrumentação que fornece elementos teóricos apropriados ao estudo da ação do sujeito, mediado por um instrumento" (BITTAR, 2011, p. 160).

Nesse sentido, não significa que o professor integra tecnologias a sua prática pedagógica ao manipular um programa de computador executando tarefas que incluam simplesmente o manejo do software, mas apenas que as inseriu, e dessa forma as tecnologias são apenas artefatos e não se constituíram ainda instrumentos integrados ao trabalho do professor. $\mathrm{O}$ educador passa a integrar tecnologias a seu trabalho, quando consegue desenvolver tarefas que promovam o ensino-aprendizagem em sala de aula, modificando a metodologia de suas aulas.

Porém, isso normalmente, está longe de ser realidade, pois de acordo Simoniam (2009, p. 62) referenciando Sancho (2006), o que ocorre na maioria dos casos é professores adaptarem o uso de recursos computacionais à forma como acreditam que ocorre a aprendizagem dos alunos, mantendo a velha metodologia utilizada em suas aulas. E dessa forma, o que acontece é moldarem o uso dessas novas tecnologias a seu trabalho em sala de aula, ao invés de aproveitarem as vantagens que estas podem oferecer para modificarem sua prática pedagógica.

Esta questão possui forte relação com a formação que recebem para o uso de recursos tecnológicos na educação, a qual quase sempre possui caráter instrumental, possibilitando o professor entender apenas como manipular o artefato, porém não oportuniza reflexões sobre possibilidades de utilização pedagógica em sala de aula. E assim, ainda que disponham de recursos tecnológicos atuais estes continuam desempenhando as mesmas funções, não ocasionando mudanças no cotidiano escolar. 
O desenvolvimento pelo homem de máquinas cada vez mais potentes, que passaram a ser empregadas para desempenhar funções antes estritamente humanas levou a divinizar essas máquinas, esquecendo-se que são suas criações, gerando o temor de que pudessem superá-lo em todas as suas funções, inclusive a de pensar e consequentemente, criar. Essa idolatria pelo material gerou a coisificação da tecnologia que passou a ser popularizada como se tecnologia fosse sinônimo de "materiais eletrônicos". De acordo com Bueno (1999, p. 86): “[...] percebe-se uma vinculação direta com o conhecimento popular e, muitas vezes com o senso comum, pois a coisificação da tecnologia implica em fazer um culto ao objeto e não ao processo e por certo, ao principal ator deste, o ser humano".

E dessa forma, o processo de evolução da tecnologia é em muitos casos esquecido e assim, corrobora-se com Bueno (1999, p. 83), que caracteriza a tecnologia como "mutualismo da técnica com a Ciência Moderna", sem dissociá-la das atividades humanas, entendendo que:

\begin{abstract}
Assim, a tecnologia não é a "coisa", o produto, pois este é o resultado de um processo mais amplo e complexo que exige do ser humano emergir em seu processo histórico; baseando-se no conhecimento científico, resultado da ciência, formular teorias a respeito das atividades dos seres humanos que, por último, faz surgir um determinado produto, um instrumento que venha a atender às necessidades não imediatas, porque a ciência por si só que é o caso da tecnologia, não pressupõe resultado imediatos (BUENO, p. 86).
\end{abstract}

Embasada em Marx, Lukács e outros autores, Bueno (2013) pesquisou como o trabalho com tecnologias educacionais nas escolas de ensino fundamental, especificamente, podem colaborar nos processos de reificação ${ }^{1}$ e superação da lógica do sistema capitalista. Para a autora, a possibilidade da superação da reificação da tecnologia no interior das escolas pode ocorrer através da consciência dos professores de que são capazes de ultrapassar os limites do ambiente de trabalho por meio da criação de espaços coletivos de discussão, repensando a concepção vigente de tecnologia.

Bueno (2013, p. 422) ousa "enfatizar ainda que torna-se urgente repensar todo o designer da escola - sua estrutura - atualmente em face da tecnologia educacional seguido da organização do trabalho pedagógico", pois o modelo vigente é o de "linha de montagem". Surge assim a necessidade de uma reflexão mais ampla, crítica e problematizadora em torno da tecnologia educacional, sendo um dos caminhos apontado pela autora, a discussão da história da tecnologia com professsores e alunos. Superando dessa forma a linha de montagem, compreendendo como, porque e com que finalidade se desenvolveu a tecnologia, despertando uma visão realmente crítica em relação à tecnologia que não se limite ao uso de artefatos ou submeta toda a proposta pedagógica "a ilusão e endeusamento da mercadoria projetada nas novas ferramentas [...]" (BUENO, 2013, p. 423).

A autora alerta também que os Projetos Políticos Pedagógicos das escolas revelam o caráter instrumental assumido pelas tecnologias, em que o professor é tido

\footnotetext{
${ }^{1}$ Deriva do latim res = coisa, reifis, tornar coisa, coisificar, portanto, pensar em algo já formatado, uma coisa um objeto, uma ação materializada que toma vida própria, no entanto, é somente a partir de uma perspectiva dialética, da teoria de Marx que a reificação ganha um caráter mais significativo, identificada e analisada à luz de uma concepção crítica de sociedade capitalista (BUENO, 2013, p. 27).
} 
nesse contexto como um "trabalhador solitário" com sua prática fragmentada já que espaços para discussões coletivas não são incentivados. Assim, atualmente: "Faz-se necessário o aprofundamento na formação continuada dos professores, destacando, sobretudo, o caráter histórico-social da tecnologia" (BUENO, 2013, p. 420). Seu trabalho sugere que a possibilidade da superação da reificação da tecnologia no interior das escolas está na tomada de consciência dos professores de que podem superar os limites da escola e da sala de aula, criando espaços coletivos de discussão, a fim de repensar a forma como a tecnologia é concebida na escola. Pois os discursos democráticos ficam presos ao papel não se concretizando nas ações que se desenvolvem no ambiente educacional.

A forma como os professores participam das decisões políticas também é muito superficial, pois se limitam a no máximo ouvir alguns que possuem um pouco mais de afinidade com as ferramentas tecnológicas (BUENO, 2013). Não há, portanto, real participação dos profissionais da educação nos processos de decisão em relação a tecnologias e tecnologias educacionais nas escolas públicas, sendo um "indicador de que o discurso da gestão democrática é apenas uma oratória" e que na verdade o que se concretiza é a mercantilização das ferramentas tecnológicas.

Bueno (2013) destaca ainda que os Projetos Políticos Pedagógicos das escolas revelam o caráter instrumental assumido pelas tecnologias, em que o professor é tido nesse contexto como um "trabalhador solitário" com sua prática fragmentada, já que espaços para discussões coletivas não são incentivados. Daí a necessidade do professor se "rebelar" contra a ridigez e burocracia do sistema e construir seu espaço, o que segundo a autora, seria o caminho apontado para a superação da reificação frente às tecnologias, a partir de uma concepção histórico-crítica e revolucionária.

Dessa forma, há necessidade de repensar a formação dos professores de modo que sejam propiciados espaços de discussão das tecnologias na educação, considerando a exclusão sócio tecnológica dos professores e suas necessidades (SIMONIAM, 2009).

Garcia (1999, apud SIMONIAM, 2009) destaca ainda a necessidade de ao formar professores viabilizar condições para realizar trabalhos em colaboração, como: "a participação na elaboração e discussão de propostas de ensino, projetos pedagógicos, análise e avaliação de materiais didáticos, incluindo também as tecnologias” (p. 64).

Pois, a educação é capaz de fornecer meios para que o povo entenda a condição em que se encontra e busque mudanças. É também um meio para adquirir conhecimento necessário às ações que almejam desvencilhar-se da submissão ao poder das nações controladoras, uma vez que a educação constitui-se como processo capaz de colocar informação em discussão e, assim, produzir conhecimento.

\section{A dinâmica do estudo}

O trabalho parte das perspectivas teóricas de Bittar (2011) e Bueno (2013) de que a formação de professores deve superar o caráter instrumental possibilitando discussões em relação a possibilidades pedagógicas de utilização de recursos tecnológicos no ensino.

Atuando desde agosto de 2012 como coordenadora do subprojeto do PIBID de Matemática da UNESPAR, campus de União da Vitória, antes intitulado Novas Tecnologias e Formação de Professores para o Ensino de Matemática (2012-2013) e 
agora Tecnologias e Formação de Professores para o Ensino de Matemática (subprojeto iniciado em 2014), observou-se a necessidade de ampliar as discussões em relação ao foco do subprojeto. Modificando inclusive sua denominação, uma vez que, o subprojeto passou a não discutir apenas as novas tecnologias, mas as tecnologias sob uma visão mais ampla, entendidas enquanto processo humano capaz de proporcionar mudanças ao ambiente escolar, em se tratando, especificamente, de tecnologias educacionais.

Participam do subprojeto alunos do primeiro ao quarto ano do curso de Licenciatura em Matemática do campus, atuando em três escolas com realidades bem diferentes: um Centro Estadual de Educação Básica para Jovens e Adultos (CEEBJA), em que o laboratório de informática funciona na biblioteca; uma escola de um bairro carente, que até bem pouco tempo atrás, embora contasse com laboratório de informática, o mesmo estava completamente sucateado, com no máximo oito máquinas funcionando e outra escola de um distrito do município que possui melhores condições em relação ao laboratório.

Dessa forma, o trabalho com computadores era dificultado em uma das escolas, principalmente pela dificuldade física com as máquinas. No CEEBJA esse tipo de dificuldade era contornado pelo número reduzido de alunos, e na outra escola, as máquinas não eram problema. Nesse sentido, nessa escola em que não havia problemas com computadores optou-se junto com o supervisor da escola e os professores da disciplina de matemática a desenvolver trabalho em contra turno com os alunos, principalmente os que apresentassem dificuldade em relação à disciplina. Assim, os bolsistas planejaram as aulas, e optaram após discussões com o professor regente, supervisor e coordenadora por tomarem como tema jogos de computador, em especial, jogos online, por considerarem que dessa forma conseguiriam motivar a aprendizagem dos alunos para a matemática.

Os alunos bolsistas desenvolvem quatro horas semanais de atividades nessas escolas com alunos das séries finais do ensino fundamental de acordo com planejamento previamente acordado entre o professor regente da turma, equipe pedagógica e supervisor da escola. Essas atividades envolvem observação de aulas, auxílio às atividades que o professor regente desenvolve, principalmente buscando atender as dificuldades individuais dos alunos das escolas. Além disso, os alunos bolsistas também realizam planejamentos de tarefas, oficinas e aulas que desenvolvem junto aos alunos da escola, as quais são integradas ao currículo, sendo desenvolvidas de acordo com os conteúdos que estão sendo trabalhados em sala de aula pelo professor da turma.

Verificou-se o desenvolvimento de inúmeros planos de aula relacionados a jogos, os quais foram aplicados pelos bolsistas do PIBID que atuavam nessa escola, mas segundo seus próprios relatos não apresentaram resultados completamente satisfatórios, ainda que os professores dos alunos tenham relatado que houve melhora na aprendizagem daqueles que participaram das atividades. Entretanto, os bolsistas relataram que os jogos, ainda que fossem do interesse dos alunos a princípio, acabaram se tornando cansativos pelo seu excesso. Vale destacar que os bolsistas foram alertados pelo supervisor e pelo coordenador de que isso poderia ocorrer, mas ainda assim, optaram por manter o foco nesse tipo de atividade, por considerarem que seria de grande interesse dos alunos. Outra questão, é que a maioria dos jogos possuía caráter de exercício de repetição e dessa forma muitas vezes os alunos acabavam tentando adivinhar os resultados e não obtinham assim ganhos em relação à aprendizagem. 
Como citado anteriormente, participam do PIBID alunos do primeiro ao quarto ano da licenciatura, e a disciplina voltada especificamente ao uso de tecnologias na educação é cursada pelos alunos apenas no último ano do curso, sendo o regime anual e não semestral. Dessa forma, ainda que fossem realizadas reuniões semanais em que se discutiam textos e tarefas relacionadas ao uso de tecnologias na educação, percebeu-se que tais questões não são tão rápida nem facilmente incorporadas pelos alunos da licenciatura que citaram que na maioria dos casos em sua escolaridade, enquanto alunos da Educação Básica não vivenciaram muitas atividades bem sucedidas de aprendizagem de matemática com o uso de recursos tecnológicos, principalmente da calculadora (rejeitada pela maioria dos professores por consideraram que esta desestimula o raciocínio dos alunos) e computador.

Nas outras duas escolas, ainda que houvesse problemas físicos em relação ao uso de computadores, esses poderiam ser utilizados através do rodízio da turma. Entretanto, foram raros os planos de aula em se observou o planejamento de atividades no laboratório de informática e quando realizadas, na maioria das vezes verificou-se que os conteúdos a serem trabalhados no laboratório de informática, antes eram trabalhados em sala de aula. Por exemplo, marcar os pontos no sistema cartesiano utilizando o software Geogebra. Antes de ser realizada essa tarefa no laboratório, tarefa similar era realizada em sala no caderno, utilizando régua e lápis. O que mostra que os bolsistas não acreditavam que os alunos pudessem aprender no computador, e viam as tarefas realizadas no laboratório como para reforçar o aprendizado, que ocorria em sala de aula.

Embora inúmeros trabalhos publicados apontem contribuições que o uso do computador pode apresentar ao ensino e consequente aprendizagem da matemática, entre os quais se cita o de Leivas (2009) que apontou possibilidades de uso de abordagens que mobilizam imaginação, intuição e visualização no ensino de conceitos geométricos em disciplinas de cursos de Licenciatura em Matemática a partir de abordagens que envolvam essas características a partir do uso de tecnologias. $\mathrm{O}$ trabalho de Barbosa (2009) indicou que a produção do conhecimento dos alunos envolvidos, acerca de função composta e regra da cadeia, ocorreram por meio de elaborações de conjecturas, formuladas durante o processo de visualização potencializado pelas TIC. Escher (2011) concluiu com seu trabalho que as TIC adquirem uma característica forte o bastante para alterar todas as dimensões teórico-metodológicas presentes nas interrelações do Cálculo Diferencial e esta no contexto de ensino e aprendizagem da matemática, assumindo, logo, seu caráter epidêmico, justificando assim sua característica revolucionária. Setti (2009) destacou que devido ao processo de discretização necessário para transformar o raciocínio matemático no correspondente computacional, é necessário utilizar os conhecimentos adquiridos previamente com um novo formato. Para conceber esta discretização, os conhecimentos matemáticos estabelecidos sofrem uma "ruptura epistemológica", pois se trata de uma mudança na forma de compreender um conhecimento.

Portanto, tomando essas observações como referência, verificou-se a necessidade de se criar espaços efetivos de discussão em relação ao uso de tecnologias no ensino da matemática, o qual tomou forma através da criação de Grupos de Trabalho, cujos resultados ainda iniciais serão discutidos a seguir. Tomou-se como referência para análise, as discussões realizadas com os bolsistas durante as reuniões, bem como seus depoimentos em relação às contribuições ou não dos trabalhos realizados e o formato do material produzido que se constituiu. 


\section{Resultados e discussão}

Desde meados de 2013 foram constituídos três grupos de trabalho que se propuseram a pesquisar e desenvolver material didático pedagógico com uso de softwares livres ou outros recursos computacionais sobre diferentes conteúdos matemáticos, divididos em três grandes conteúdos estruturantes: Geometrias, Números e Álgebra e, Estatística e Probabilidade.

Até o início de 2014, os grupos reuniam-se semanalmente por um período de duas horas. Dessa forma, num primeiro momento eram realizadas discussões teóricas com textos previamente selecionados e encaminhamentos gerais do subprojeto com todos os envolvidos. Depois, os alunos se dividiam nos subgrupos e sob orientação de professores da universidade, juntamente com professores das escolas de educação básica que atuam como supervisores do subprojeto passavam a discutir, pesquisar e desenvolver tarefas a serem realizadas com o uso do computador, a fim de facilitar o processo de ensino-aprendizagem de matemática.

No início de 2014, modificou-se a dinâmica do trabalho, passando a serem realizados encontros quinzenais de quatro horas, a fim de manter a continuidade e foco das discussões no trabalho. Pois na avaliação realizada em relação ao rendimento dos grupos, um dos apontamentos foi do curto tempo contínuo dos trabalhos nos grupos, tendo sido relatado que muitas vezes quando o trabalho "engajava" tinham que parar porque precisavam encerrar as atividades por causa do horário.

Entretanto, foi unânime a opinião dos bolsistas de que aprenderam muito com os grupos, que mesmo nos casos em que certas projeções que haviam feito não se concretizaram, ainda assim esse tempo foi importante para estudarem, aprenderem e discutirem os conteúdos e, em muitos casos, verificarem inclusive limitações dos softwares. Como exemplo, pode ser citado o grupo que estuda as Geometrias, cuja ideia inicial era trabalhar com a Geometria não euclidiana, e durante os estudos verificaram a necessidade de primeiro se trabalhar com os conteúdos da Geometria euclidiana, pois estavam encontrando muitas limitações em relação às possibilidades que os softwares ofereciam. Entretanto, destacaram que o período que trabalharam com a Geometria não euclidiana não foi desperdiçado, pois aprenderam muito sobre o conteúdo.

Outro ponto a se enaltecer é que muitos declararam que antes não consideravam ser possível aprender matemática com o uso de recursos computacionais, e depois dos trabalhos realizados nos grupos perceberam ser possível. Relataram que aprenderam também em relação à linguagem a ser utilizada ao se produzir material didático que seja acessível a alunos de diferentes níveis. $\mathrm{E}$ a propor questões que permitam ao aluno refletir sobre o conteúdo estudado para responder aos questionamentos e, dessa forma entendê-lo, assim construindo seu conhecimento matemático. Como pode ser verificado no relato de um professor supervisor e de um aluno bolsista em relação as contribuições que sua participação nos grupos do subprojeto proporcionaram a sua formação:

Repensar os conceitos que envolvem as operações com frações. Analisar o texto em 3 aspectos diferentes: como escritor, como aluno que irá interpretar o material e como professor que irá utilizar o material. Essa analise exige um esforço intelectual dinâmico e complexo, pois se divide em 3 aspectos a ser analisado em um só momento e em um mesmo conteúdo (Professor Supervisor PIBID, 2014). 


\begin{abstract}
Iniciamos o desenvolvimento de um material didático sobre frações. Ao pesquisar a construção deste material nos deparamos com inúmeras dificuldades, tais como a linguagem, o conhecimento prévio dos estudantes, entre outros. Analisando estas dificuldades percebemos que para o aluno realmente compreender, os professores devem ter pleno domínio do conteúdo a ser trabalhado e a forma com a qual irá induzir os estudantes a aprenderem o mesmo.Com as pesquisas realizadas por meio do programa, aprendi muito sobre o ensino de frações e como é possível realizar associações para facilitar a compreensão dos estudantes, assim como a linguem a ser utilizada no ensino fundamental. Os estudos realizados também possibilitaram uma melhor compreensão de como é dada a dinâmica em sala de aula, da interação entre professor e alunos e do próprio conhecimento matemático (Aluno Bolsista PIBID, 2014).
\end{abstract}

Além disso, o formato do material produzido permite verificar a diferença entre o material proposto anteriormente e o que está em produção, pois prevê que o aluno através da manipulação de ferramentas construa seu conhecimento e não apenas execute passo a passo tarefas repetitivas.

\title{
5. Considerações finais
}

As tarefas até o momento foram elaboradas e propostas utilizando o software livre Geogebra. A precariedade dos equipamentos nas escolas, em muitos casos, dificulta o trabalho, pois a falta de atualização dos softwares e equipamentos disponíveis muitas vezes atrapalha o desenvolvimento do trabalho, precisando adaptar o material à versão do programa disponibilizado na escola, para que seja possível executá-lo em todas as máquinas nos laboratórios.

Em muitas situações essa dificuldade de material adequado é também presenciada na própria universidade, que não dispõe de muitos recursos que poderiam contribuir para o aprendizado da matemática.

A fim de contribuir para amenizar essas dificuldades encontrou-se apoio financeiro no LIFE (Laboratórios Interdisciplinares de Formação de Educadores) que possibilitou a compra de equipamentos que permitem a realização de atividades que antes não podiam ser executadas por falta de material, entre as quais pode ser citada, no caso de matemática especificamente, do estudo do uso de calculadoras gráficas no ensino de matemática.

A formação de grupos de trabalho para elaboração de tarefas de matemática de cunho exploratório visando que o aluno aprenda os conteúdos da disciplina com o uso de ferramentas computacionais de forma mais dinâmica e interativa, possibilitou reflexões dos bolsistas também em relação às outras metodologias de ensino, pois tiveram que refletir sobre como questionar os alunos utilizando linguagem apropriada para que compreendam o que está sendo perguntado e assim consigam através das questões propostas construir seu conhecimento. Nesse sentido, as tarefas propostas com o uso do computador propuseram mudanças no processo de aprendizagem, em que o aluno deixa de meramente repetir algoritmos apresentados pelo professor para buscar respostas às questões apresentadas. 
Além disso, antes os bolsistas costumavam simplesmente buscar atividades prontas para desenvolverem com os alunos, e a partir daí passaram a produzir tarefas, utilizando o computador como instrumento no ensino de conteúdos de matemática.

Assim o trabalho até aqui desenvolvido mostrou avanços na formação dos professores para o ensino da matemática e para que reflitam sobre a aprendizagem dos alunos na disciplina.

Por outro lado, ainda há muitos desafios a superar, e questões a serem avaliadas no desenvolvimento do trabalho, entre os quais os resultados na aprendizagem dos alunos nas escolas. Pois como citado, os alunos bolsistas desenvolvem semanalmente em três escolas atividades com alunos das séries finais do ensino fundamental. Entretanto em muitos casos, o desenvolvimento de tarefas com o uso de computadores é dificultada e até mesmo impossibilitada pela falta de equipamentos funcionando adequadamente. E quando funcionam, muitas vezes estão tão obsoletos que não suportam os arquivos preparados. E muitas vezes as tarefas preparadas precisam ser adaptadas para poderem ser desenvolvidas.

Entretanto, pode-se dizer que o trabalho é positivo para a escola ao dinamizar o processo de ensino e aprendizagem e mobiliar a necessidade da atualização dos recursos informáticos da escola.

\section{Referências}

Barbosa, S. M. (2009) "Tecnologias da Informação e Comunicação, Função Composta e Regra da Cadeia". Tese (Doutorado em Educação Matemática). Rio Claro: Universidade Estadual Paulista Júlio de Mesquita Filho.

Bittar, M. (2011) "A abordagem instrumental para o estudo da integração da tecnologia na prática pedagógica do professor de matemática", Educar em Revista: Editora UFPR, Curitiba, Brasil, n. Especial 1/2011, p. 157-171.

Bueno, N. L. (2013) "Tecnologia Educacional e Reificação: Uma Abordagem Crítica a Partir de Marxs e Luckás”. Tese (Doutorado em Educação). Curitiba: Universidade Federal do Paraná.

Escher, M. A. (2011) "Dimensões Teórico-Metodológicas do Cálculo Diferencial e Integral: perspectivas histórica e de ensino e aprendizagem". Tese (Doutorado em Educação Matemática). Rio Claro: Universidade Estadual Paulista Júlio de Mesquita Filho.

Leivas, J. Ca. P. (2009) "Imaginação, Intuição e Visualização: A Riqueza de Possibilidades da Abordagem Geométrica no Currículo de Cursos de Licenciatura de Matemática". Tese. (Doutorado em Educação). Curitiba: Universidade Federal do Paraná.

Odorico, E. K., Nunes, D. M., Moreira, A., Oliveira, H. M. P. de e Cardoso, A. (2012) "Análise do Não Uso do Laboratório de Informática nas Escolas Públicas e Estudo de Caso". Anais do $18^{\circ}$ Workshop de Informática na Escola: Rio de Janeiro, RJ, Brasil.

Setti, M. de O. G. (2009). “O Processo de Discretização do Raciocínio Matemático na Tradução para o Raciocínio Computacional: Um Estudo de Caso no 
Ensino/Aprendizagem de Algoritmos". Tese (Doutorado em Educação). Curitiba: Universidade Federal do Paraná.

Simonian, M. (2009) "Formação continuada em ambiente virtual de aprendizagem: elementos reveladores da experiência de professores da educação básica". Dissertação (Mestrado em Educação). Curitiba: Universidade Federal do Paraná. 